\title{
Understanding differences in HIV/HCV prevalence according to differentiated risk behaviors in a sample of PWID in rural Puerto Rico
}

\author{
Roberto Abadie ${ }^{1 *}$, Melissa Welch-Lazoritz ${ }^{1}$, Camila Gelpi-Acosta ${ }^{2}$, Juan Carlos Reyes ${ }^{3}$ and Kirk Dombrowski ${ }^{1}$
}

\begin{abstract}
Background: Blood contained in needles and injection equipment has been identified as a vector for HIV and HCV transmission among people who inject drugs (PWID). Yet, there is often a wide discrepancy in prevalence for both viruses. While microbiological differences between viruses influence prevalence, other variables associated with the way drugs are acquired and used, also play a role.

Methods: Respondent-driven sampling (RDS) methods recruited a sample of 315 current intravenous drug users in rural Puerto Rico. Information about type and frequency of use, HIV and HVC risk behaviors (sharing needles, cookers, cotton, and water), sexual behaviors, and alcohol use was collected. HIV and HCV statuses were assessed via rapid antibody tests. $T$ tests compare means of participants who tested positive (reactive) to those who tested negative. Logistic regression analyses were used to validate the association of the risk factors involved.

Results: Tests showed a significant difference in HIV (6 \%) and HCV (78.4\%) prevalence among a population of current PWID. The main risk behaviors in HCV transmission are the sharing of injection "works", (e.g., cookers, cotton, and water). Sharing works occurred more than twice as often as the sharing of needles, and HCV+ and HCV- individuals reported the same needle sharing habits.

Conclusions: Washing and rinsing injection works with water seems to prevent HIV transmission, but it is unable to prevent HCV infection. While education about the need to clean injection equipment with bleach might be beneficial, equipment sharing — and the subsequent risk of HVC — might be unavoidable in a context where participants are forced to pool resources to acquire and use intravenous drugs.
\end{abstract}

Keywords: HIV-HCV risk factors, PWID, Sharing, Injection equipment, Rural Puerto Rico

\section{Background}

The current 2015 study of people who inject drugs (PWID) in rural Puerto Rico found that $6.0 \%$ of the sample was HIV positive while $78.4 \%$ of the sample was Hepatitis C (HCV) positive using rapid tests. Research has shown that PWID in Puerto Rico are at a very high risk for HIV, as injection drug use is the most important factor behind the prevalence of HIV on the island [1-4]. Puerto Rico occupies the sixth place in HIV prevalence

\footnotetext{
* Correspondence: rabadie2@unl.edu

1 Department of Sociology, University of Nebraska-Lincoln, 206 Benton Hall, Lincoln, NE 68588, USA

Full list of author information is available at the end of the article
}

among all US states and territories [5]. Injection drug use is responsible for almost half of the accumulated AIDS cases and nearly $26 \%$ of HIV cases diagnosed between 2005 and 2011. In 2010, PWID accounted for $8.6 \%$ of new HIV infections across the USA, while the proportion in Puerto Rico was over two times greater (20.4 \%) [6]. A study by Reyes et al. among PWID in the metropolitan San Juan area places HIV prevalence at $17 \%$ and $\mathrm{HCV}$ prevalence at a striking $89 \%$ [7].

Studies have documented wide discrepancies in the prevalence of HIV and HCV among PWID across the world $[8,9]$. Research has identified the main causes of transmission for both viruses as blood contained in the 
syringes, cookers, cotton, and water [10, 11]. Still, PWID appear to be more vulnerable to HCV than to HIV. The microbiological properties of $\mathrm{HCV}$ are considered one of the main reasons behind these prevalence discrepancies [12]. Indeed, $\mathrm{HCV}$ is more potent and resilient than the HIV virus and can live on surfaces of the body for up to 6 weeks while maintaining infectivity $[13,14]$. Years of injection, using in shooting galleries, incarceration, number of injection partners, and history of sexually transmitted diseases have been associated with higher rates of HCV acquisition among PWID [15-17]. In Puerto Rico, lack of knowledge of the HCV and lack of awareness of $\mathrm{HCV}$ serostatus have also been identified as factors behind transmission [18].

Various researchers $[19,20]$ have suggested that the sharing of injection equipment, such as cookers and cotton, could be contributing to $\mathrm{HCV}$ transmission vulnerability for PWID. Indeed, many argue that PWID may be sharing cookers, cottons, and water more often than they are sharing syringes, and this is particularly true since the advent of needle exchange programs in the USA [21]. Another study with PWID in Denver, CO, found that while just $22 \%$ of users shared needles, $86 \%$ used a common cooker to divide drugs [22].

Our study seeks to explore these risk factors among rural Puerto Rican PWID, a population whose risk behaviors have never before been studied, perhaps due to the difficulties of accessing a marginalized population. We also aim to contribute to the literature by comparing the risk behaviors of $\mathrm{HCV}$ positive and HCV negative PWID in rural Puerto Rico. By outlining the similarities and differences in risk behaviors between these two groups, we will help identify the service needs to be addressed to arrest the further spread of $\mathrm{HCV}$ among PWID in Puerto Rico and abroad.

\section{Methods \\ Data}

This paper utilizes data from 315 PWID residing in Cidra, Comerio, Aguas Buenas, and Cayey, four rural towns in the mountainous area of central Puerto Rico, about 30-40 miles from San Juan. Sites were selected because they were representative of rural PWID on the island [23]. In addition, these sites were chosen due to the presence of El Punto en la Montaña, the only syringe exchange program operating in rural Puerto Rico, with whom we established a close collaboration that facilitated data collection with this population. Interviews were completed between April 2015 and June 2015. Sample recruitment was managed using respondent-driven sampling (RDS) and we started two seeds in each of the four towns (for a total of 8 seeds, 307 recruits). Participants who completed the survey were given three referral coupons to pass out to other PWID they knew and who had not previously participated in the study. Every eligible referral earned the recruiter an additional $\$ 10$. Upon completion of the questionnaire, participants were given $\$ 25$. RDS has proven effective in recruiting hard to reach populations [24-27]. Participants were 18 years of age or older, alert at the time of the interview, and had injected drugs within the past 30 days. Verification of current injection use was done through visual inspection of injection track marks as well as through a questionnaire that measuring knowledge of injection practices [28, 29].

The questionnaire was interviewer-administered and based off of the CDC NHBS IDU Round 3 Questionnaire version 13. In addition to demographic variables, we collected information about type and frequency of drug use, as well as HIV and HCV risk behaviors such as sharing of needles, cookers, cotton, and water in addition to sexual behaviors and alcohol use. HIV and HCV status was assessed through the use of INSTI Rapid HIV antibody tests (Biolytical Laboratories) and OraQuick HCV Rapid antibody tests (OraSure Technologies). Every participant was compensated an additional $\$ 5$ for each rapid test performed. Participants who tested positive for HCV or HIV were offered referral and transportation to a primary care doctor for confirmatory testing. The study received IRB approval through the University of Nebraska-Lincoln (IRB\# 20131113844FB) and the University of Puerto Rico School of Medicine (IRB\# A8480115).

\section{Measures}

HIV status and HCV status were determined by the results of the INSTI Rapid HIV and OraQuick Rapid $\mathrm{HCV}$ test. Annual per capita income was assessed by two questionnaire items, one which participants selected an income bracket and a second which participants reported how many people rely on that income during the year. The upper limit of the income bracket was then divided by the number of people relying on income to achieve an approximation of annual per capita income. Percent unemployed was assessed using a question that asked participants which best described their employment status: employed full time, employed part time, full time student, retired, unable to work for health reasons, unemployed, or other.

Frequency of injection was assessed using the question "in the last 12 months, on average, how often did you inject drugs?" with response choices of (1) one time per month, (2) 2-3 times per month, (3) one time per week, (4) 2-6 times per week, (5) one time per day, (6) 2-3 times per day, and (7) 4 or more times per day. Number of people used needle is a continuous measure based on the question "with how many people did you use a needle after they injected with it?", this question was framed in the context of both "in the past 12 months" and "in the past month". Number of people used works is also a continuous measure 
from the question "with how many people did you use the same cooker, cotton, or water that they had already used?" with responses for past year and past month. Number of people backloaded is a continuous measure assessing with how many people the participant used drugs that had been divided with a syringe that they had already used (i.e., backloading, frontloading), in the past year and in the past month.

Frequency of (1) used needle utilization, (2) used cooker utilization, (3) used cotton utilization, and (4) used water utilization are four categorical measures asking how often, in the past year, the participant used (1) needles that someone else had already injected with, (2) a cooker that someone else had already used, (3) a cotton that someone else had already used, and (4) water that someone else had already used. The response options are never (coded as 0 ), rarely (coded as 1 ), about half of the time (coded as 2), most of the time (coded as 3), and always (coded as 4).

\section{Analytic approach}

Analysis of the RDS data was undertaken using both of the current, accepted RDS analysis platforms: RDSAT version 7.1 [30] and RDS Analyst [31]. No significant differences in results were found between the two routines. Dual homophily scores were calculated for the main demographic variables, including gender, age, HIV and HCV status, drug treatment participation, drug choice, number of sex partners, geographic location of recruitment, frequency of drug use, income, and homelessness in the past year. For the demographic variables (age, gender, income, location, and homeless status), no significant biases were discovered. Complex homophily results were found for individual variable values on drug of choice (only use of speedball was significant, other drugs were not), HCV status (only known positive status was significant) and treatment participation. As none of these influenced the demographic variables, the analyses discussed here were made from sample point estimates, unadjusted by RDS results. A full discussion of the RDS sample and its analysis is currently under review in the Puerto Rican Public Health Sciences Journal.

The results reported in this analysis stem from $t$ tests to compare the means of participants who tested positive (reactive) for HCV antibodies in the rapid test, and participants who tested negative for HCV antibodies on several variables, including injection habits. Multivariate analyses using logistic regression were used to further evaluate the association of risk factors shown in the comparison of means tests. We conducted a logistic regression with each variable tested in Table 2 and controlled for gender (male), age, per capita income, education level (high school graduate or better), marital status (married or cohabiting), and number of years spent injecting drugs. All analyses were conducted using IBM SPSS Statistics software.

\section{Results}

Table 1 presents demographic data for study participants. More than three quarters $(78.4 \%)$ tested positive for $\mathrm{HCV}$ during the rapid test, while $6.0 \%$ tested positive for HIV. All 19 HIV positive participants were HCV co-infected. Approximately $90.5 \%(n=285)$ were male and $93.0 \%$ were born in Puerto Rico. Almost all PWID who were not born in Puerto Rico had been born in the continental United States. The sample had a mean age of 41.8 years (range 18-70 years) and an average annual per capita income of $\$ 4452$. Participants were mostly (85.4\%) unemployed, $21.9 \%$ were homeless at the time of their interview, and $52.4 \%$ were high school graduates (or higher). Only $2.9 \%$ of participants were currently married, though an additional $19.3 \%$ were living together as married, while $47 \%$ were single and never married (the remaining $30.8 \%$ were separated, divorced, or widowed).

As shown in Table 2, commonalities in injection behaviors regardless of HCV status are apparent. For instance, both groups reported injecting drugs at the same average frequency during the past year. In addition, past year utilization of used needles and the number of people who used needles before them are exactly the same. However, significant differences between $\mathrm{HCV}$ statuses shed some light over the vast disparity between $\mathrm{HIV}$ and $\mathrm{HCV}$ infection found in rural Puerto Rico. First, $\mathrm{HCV}+$ injectors are, on average, 3 years older than their HCV- counterparts $(p \leq .031)$. Second, those who were $\mathrm{HCV}+$ began injecting drugs at a much younger age (20.7 years) than those $\mathrm{HCV}$ - participants (26.3 years; $p \leq .001)$; and third, $\mathrm{HCV}+$ participants have spent 9.4 more years injecting drugs than their $\mathrm{HCV}$ - counterparts $(p \leq .001)$.

Importantly, marked differences in their use of works are of note. Specifically, HCV+ participants used injection preparation equipment (cooker, cotton, and/or water) after an average of almost 2 more people in the past year

Table 1 Descriptive statistics

\begin{tabular}{llll}
\hline & Mean/\% & SD & N \\
\hline \% HIV positive (INSTI Rapid Test) & $6.0 \%$ & & 315 \\
\% HCV positive (OraQuick Rapid Test) & $78.4 \%$ & 315 \\
\% Male & $90.5 \%$ & 315 \\
\% Born in Puerto Rico & $93.0 \%$ & & 315 \\
Age (years) & 41.8 & $(10.07)$ & 315 \\
Annual per capita income & $\$ 4452$ & $(\$ 3200)$ & 311 \\
\% Unemployed & $85.4 \%$ & & 314 \\
\% Currently homeless & $21.9 \%$ & & 314 \\
\% Graduate high school (or higher) & $52.4 \%$ & 315 \\
\% Married or living together as married & $22.2 \%$ & 315 \\
\% Injected 4 or more times per day & $39.7 \%$ & 315 \\
\% Injected 2-3 times per day & $39.7 \%$ & 315 \\
\hline
\end{tabular}


Table 2 Comparison of means for injecting practices by HCV status

\begin{tabular}{|c|c|c|c|}
\hline & $\mathrm{HCV}+(n=247)$ & $\mathrm{HCV}-(n=68)$ & N \\
\hline Age (years) & $41.8^{*}$ & $38.8^{*}$ & 315 \\
\hline Age at first use of injection drugs & $20.7^{* * *}$ & $26.3^{* * *}$ & 315 \\
\hline \# of years injecting drugs & $21.9^{* * *}$ & $12.5^{* * *}$ & 315 \\
\hline \multicolumn{4}{|l|}{ Past year: } \\
\hline Frequency of injection & 5.9 & 5.9 & 315 \\
\hline \# of people used needle & 1.2 & 1.2 & 314 \\
\hline \# of people used works & 4.9 & 3.0 & 314 \\
\hline \# of people backloaded & 1.5 & 0.91 & 311 \\
\hline Frequency of used needle utilization & 0.4 & 0.4 & 315 \\
\hline Frequency of used cooker utilization & $1.1^{*}$ & $0.8^{*}$ & 315 \\
\hline Frequency of used cotton utilization & 0.8 & 0.6 & 315 \\
\hline Frequency of used water utilization & 0.7 & 0.5 & 315 \\
\hline \multicolumn{4}{|l|}{ Past month: } \\
\hline \# of people used needle & 0.4 & 0.5 & 315 \\
\hline \# of people used work & $2.0^{* *}$ & $1.0^{* *}$ & 315 \\
\hline \# of people backloaded & 0.6 & 0.5 & 313 \\
\hline
\end{tabular}

than their HCV- counterparts (4.9 people compared to 3.0 people, $p \leq .122$; though not significant at standard $p$ values, this large difference is notable). In the past year, $\mathrm{HCV}+$ participants backloaded after an average of .6 more people $(p \leq .086)$ and injected with a used cooker significantly more frequently $(p \leq .034)$ than $\mathrm{HCV}$ - participants. In the past month, $\mathrm{HCV}+$ injectors used works after 1 more person than those without HCV $(p \leq .001)$.

After controlling for gender, age, annual per capita income, marital status, and level of education, the significance of the results from the comparison of means holds up (the entire logistic regression table is available online as Additional file 1 to this paper). Logistic regression results indicate that for every one-unit increase in the frequency of past year used cooker utilization, there is a $26 \%$ increase in the odds of being HCV+ $(p \leq .029)$. Each additional person who used works before the participant during the past month is associated with an $18 \%$ increase in the odds of being $\mathrm{HCV}+(p \leq .039)$. Interestingly, no measurements of needle sharing behaviors were statistically significant predictors of $\mathrm{HCV}$.

The number of people who used works before a participant in the last year (4.9 $\mathrm{HCV}+$ and $3.0 \mathrm{HCV}-)$ is more than double (or quadruple for $\mathrm{HCV}+$ injectors) the number of people who used a needle before a participant in the past year (1.2 for both $\mathrm{HCV}+$ and $\mathrm{HCV}-$ ). Similarly, the past year frequency of injecting with a used cooker was at least double that of injection with a used needle. Clearly, needle sharing was not the main mechanism for $\mathrm{HCV}$ transmission among rural Puerto Rican PWID.

\section{Discussion}

This study found an HIV prevalence of $6 \%$ and an HCV prevalence of $78.4 \%$ among a sample of intravenous drug users in rural Puerto Rico. This prevalence for HCV is among the highest in the world [32-35]. A systematic review of 77 countries found a mid-point prevalence estimate for HCV among PWID between 60 and $80 \%$ in 25 countries and more than $80 \%$ in 12 countries [36].

Our results indicate that $\mathrm{HCV}$ risk lies in sharing works, or specifically cookers, and this could be especially problematic for disease contraction because of HCV's ability to live outside the body for many days [37], and its ability to spread with only a very small concentration of blood that could be found in drug using equipment, even after rinsing with clean water [38]. Age, the number of people who had used works before the participant, and frequency of used cooker utilization are all significantly higher for individuals with $\mathrm{HCV}$. While sharing needles, cookers, cotton, and water has been outlined as a main risk for both HIV and HCV, our study shows that the main risk for $\mathrm{HCV}$ infection, given current behaviors, is associated with sharing cookers more than with using needles after somebody else had used them. This builds upon research [39-42] showing that an important proportion of $\mathrm{HCV}$ infections are likely attributable to cooker or cotton sharing.

Sharing works could very well be related to the rural injectors' needs to pool resources to acquire the drugs. The most commonly injected drug for our sample is speedball, a mix of heroin and cocaine, and most participants inject 
multiple times per day. In the four municipalities where study participants reside, the approximate cost of a small bag of heroin is $\$ 6$, and $\$ 5$ for a small bag of cocaine, thus requiring \$11 for one single injection event. One means to deal with this is to pool resources and share the drugs. Further, speedball use is often associated with high frequency of injection [43]. This represents a significant challenge for the current sample of rural Puerto Rican injectors, who have an average per capita annual income of just \$4452. When sharing, users mix the purchased heroin and cocaine bags in the same cooker before injecting. In fact, this practice is commonly called "caballo", or horse, in rural Puerto Rico. Once the drug is dissolved in the cooker, injectors can collect their "share" via separate or shared syringe, taking turns. Others might prefer to backload. Dissolving the pooled drug in the same cooker may also be leading participants to using the same cotton to filter the drug.

In addition to the hardy virological properties of $\mathrm{HCV}$, another factor contributes to the epidemic is lack of HCV treatment. While $82.5 \%$ of our sample has state sponsored health insurance coverage (Reforma), many are unable to access HCV treatment, as the state health insurance plan will not cover this expensive treatment unless the patient is also HIV positive. Barriers to $\mathrm{HCV}$ treatment in the island have been also previously described [44] and as such, the vast majority of HCV patients carry the virus for many years [45].

Finally, interventions designed to provide more education to PWID about the particular viral characteristics of $\mathrm{HCV}$ and its strong transmission risk would be beneficial. Other strategies to reduce the prevalence of $\mathrm{HCV}$ among this population include more extensive testing and counseling, along with efforts to scale up HCV treatment for those that have tested positive to $\mathrm{HCV}$, especially in resource-rich countries $[46,47]$. However, while these interventions, as well as other more general harm reduction strategies like providing safe injection rooms [48] or extending the presence of needle exchange programs $[49,50]$ are advisable, the financial incentive to pool resources to jointly acquire and use the drugs continues to be a significant obstacle to curb the spread of $\mathrm{HCV}$ in this population. Furthermore, migration patterns, especially across borders, might complicate prevention efforts by making PWID harder to reach, or by introducing the risk of $\mathrm{HIV} / \mathrm{HCV}$ infection in other social networks $[51,52]$.

\section{Limitations}

One limitation resides in the fact that while RDS is a standard methodology for reaching marginalized populations, we cannot be sure that our sample completely accounts for the entire population of rural injectors. Another constrain is that this study asked participants about frequency of drug use at different intervals, spanning from the past month, to the past year. It is not possible to exclude the possibility of recall bias, especially when participants are asked to remember information from practices far removed from the present. Despite this limitation, we believe that probing participant about drug frequency at different time intervals is justified by the need to document potential changes in drug use patterns over time. This study is further limited in its reliance on self-reports rather than observed risk behaviors. While asking participants about their risk practices illuminates the risks they face in the course of injecting drugs, it remains a less precise alternative when compared with directly observing these same behaviors. The interpretation of data about co-infection of HIV and HCV is limited because our survey did not collect temporal data about which infection came first, obscuring the fact that PWID living with HIV $(n=19)$ are more likely to contract $\mathrm{HCV}$.

\section{Conclusions}

The wide discrepancy in prevalence between HIV and HCV among PWID in rural Puerto Rico does not have a single explanation. Nevertheless, this study found considerable evidence that $\mathrm{HCV}$ transmission is occurring in association with the shared use of contaminated cookers, cotton, and water, rather than via syringes. Future research should consider studying $\mathrm{HCV}$ infectivity in injection works, like cookers and cottons, following Paintsil et al.'s 2010 study on HCV infectivity in low and high volume syringes [14]. Also, HCV education might not overcome participants' needs to pool resources. Finally, adding health insurance coverage for HCV treatment, and particularly so for impoverished Puerto Ricans, might help improve HCV screening and testing, diminishing the pool of HCV-infected PWID and, in turn, slowing the spread and lowering the overall prevalence of $\mathrm{HCV}$ among this population.

\section{Additional file}

Additional file 1: Table S1. HCV+ result logistic regression $(n=308)$. (DOCX $21 \mathrm{~kb})$

\section{Competing interests \\ The authors declare that they have no competing interests.}

Authors' contributions

RA conducted data collection and drafted the manuscript. MW coordinated the study and performed the data analysis. CG and JCR revised the manuscript and offered substantial revision. KD conceived, designed, and coordinated the study and helped to draft the manuscript. All authors read and approved the final manuscript.

\section{Acknowledgements}

This work was supported by the National Institute on Drug Abuse of the National Institutes of Health [grant number R01DA037117] and by the Center for Drug Use and HIV Research [CDUHR-P30 DA011041]. The content is solely the responsibility of the authors and does not necessarily represent the official views of the National Institutes of Health. 


\section{Author details}

'Department of Sociology, University of Nebraska-Lincoln, 206 Benton Hall, Lincoln, NE 68588, USA. ${ }^{2}$ Social Science Department, LaGuardia Community College, 31-10 Thomson Ave., Long Island City, NY 11101, USA. ${ }^{3}$ Department of Biostatistics and Epidemiology, University of Puerto Rico, 365067, San Juan, PR 00936, USA

\section{Received: 13 November 2015 Accepted: 2 March 2016}

Published online: 08 March 2016

\section{References}

1. Diaz T, Buehler J, Castro K, Ward J. AIDS trends among Hispanics in the United States. Am J Pub Health. 1993;83:504-9.

2. Robles RR, Colón HM, Sahai H, Matos TD, Marrero CA, Reyes JC. Behavioral risk factors and human immunodeficiency virus (HIV) prevalence among intravenous drug users in Puerto Rico. Am J Epidemiol. 1992;135:531-40.

3. Selik R, Castro K, Pappaioanou M. Racial/ethnic differences in the risk of AIDS in the United States. Am J Pub Health. 1988;78:1539-45.

4. Deren S, Robles R, Andia J, Colon H, Kang S, Perlis T. Trends in HIV seroprevalence and needle sharing among Puerto Rican drug injectors in Puerto Rico and New York. J Acquir Immune Defic Syndr. 2001;26:164-9.

5. Centers for Disease Control and Prevention. HIV Surveillance Report, 2011, vol. 23. 2013.

6. Department of Health of Puerto Rico. Perfil Epidemiológico Integrado para la Prevención del VIH en Puerto Rico, 2005-2011. San Juan, Puerto Rico: Department of Health of Puerto Rico; 2012.

7. Reyes JC, Colon H, Robles RR, et al. Prevalence and correlates of hepatitis virus infection among street-recruited injection drug users in San Juan, Puerto Rico. J Urban Health. 2006:83(6):1105-13.

8. Bao YP, Li ZM. Systematic review of HIV and HCV infection among drug users in China. Int J STD AIDS. 2009:20:399-405.

9. Rahimi-Movaghar A, Razaghi EM, Sahim-Izadian E, Amin-Esmaeili M. HIV, hepatitis $C$ virus, and hepatitis B co-infections among injecting drug users in Tehran, Iran. Int J Infect Dis. 2010;14:28-33.

10. Hahn A, Page-Schafer K, Lum PJ, et al. Hepatitis c virus seroconversion among young injection drug users: relationships and risk. J Infect Dis. 2002; 186:1558-64.

11. Doerrbecker J, Behrendt P, Matheu-Gelabert $P$, et al. Transmission of Hepatitis C Among People Who Inject Drugs: Viral Stability And Association with Drug Preparation Equipment. J Infect Dis. 2013; 207(2):281-7.

12. Pouget $\mathrm{E}$, Hagan $\mathrm{H}$, Des Jarlais D. Meta-analysis of hepatitis $\mathrm{C}$ seroconversion in relation to shared syringes and drug preparation equipment. Addiction. 2012; 107:1057-65.

13. Paintsil E, Binka M, Patel A, Lindenbach BD, Heimer R. Hepatitis C virus maintains infectivity for weeks after drying on inanimate surfaces at room temperature: implications for risk transmission. J Infect Dis. 2014:209:1205-11.

14. Paintsil $E, H e H$, Peters $C$, Lindenbach BD, Heimer R. Survival of hepatitis $C$ virus in syringes: implication for transmission among injection drug users. J Infect Dis. 2010;202:984-90.

15. Miller CL, Johnston C, Spittal RM, Liu K, Laliberte N, Montaner JS, et al. Opportunities for prevention: hepatitis C prevalence in a cohort of young injection drug users. Hepatol. 2002;36:733-42.

16. Dolan K, Teutsch S, Schever N, Levy M, Rawlinson W, Lloyd A, et al. Incidence and risk for acute hepatitis c infection during imprisonment in Australia. Eur J Epidemiol. 2010:25:143-8.

17. Rolls D, Sacks-Davis R, Jenkinson R, et al. Hepatitis C transmission and treatment in contact networks of people who inject drugs. PLOS One. 2013;8:e78286

18. Pérez CM, Albizu-García CE, Torres EA. Tackling the health challenge posed by hepatitis $C$ in Puerto Rico: a call for immediate public health actions. P R Health Sci J. 2015:34:53-9.

19. Zibbell JE, Hart-Malloy R, Barry J, Fan L, Flanigan C. Risk factors for HCV infection among young adults in rural New York who inject prescription opioid analgesics. Am J Public Health. 2014:104:2226-32.

20. Hagan $\mathrm{H}$, Thiede $\mathrm{H}$, Noel $\mathrm{S}$, et al. Sharing of drug preparation equipment as a risk factor for hepatitis C. Am J Public Health. 2001:91:42-6.

21. Hagan H, Des Jarlais D, Friedman S, Purchase D, Alter MJ. Reduced risk of hepattis $B$ and hepatitis $C$ among injection drug users in the Tacoma Syringe Exchange Program. Am J Public Health. 1995;85:1531-7.

22. Koester S, Glanz J, Baron A. Drug sharing among heroin networks: implications for HIV and hepatitis B and C prevention. AIDS Behav. 2005;9:27-39.
23. López LM, de Saxe Zerden L, Bourgois P, et al. HIV/AIDS in Puerto Rican people who inject drugs: policy considerations. Am J Public Health. 2015; 105(1):e3.

24. Abdul-Quander AS, Heckathorn DD, McKnight C, Bramson H, Nemeth C, Sabin $\mathrm{K}$, et al. Effectiveness of respondent driven sampling for recruiting drug users in New York City: findings from a pilot study. J Urban Health. 2006:83:459-76

25. Heckathorn DD. Respondent-driven sampling II: deriving valid population estimates from chain-referral samples of hidden populations. Social Problems. 2002;49:11-34

26. Heckathorn DD. Extensions of respondent-driven sampling: analyzing continuous variables and controlling for differential recruitment. Sociol Methodol. 2007:37:151-207.

27. Johnston LG, Chen YH, Silva-Santisteban A, Raymond HF. An empirical examination of respondent driven sampling design effects among HIV risk groups from studies conducted around the world. AIDS Behav. 2013;17:2202-10.

28. Cagle $H$, Fisher D, Senter T, Thurmond R. Classifying skin lesions of injection drug users: a method for corroborating disease risk. DHHS Pub. No. (SMA) 03-3771. Rockville, MD: Center for Substance Abuse Treatment, Substance Abuse and Mental Health Services Administration; 2002.

29. Fisher D, Needle R, Weatherby N, Brown B, Booth R, Williams M. Reliability of drug user self report. In: Abstract Book, IX International Conference on AIDS, June 6-11, 1993; Berlin, Germany, Abstract no. PO-C35-3355.

30. Volz E, Wejnert C, Cameron C, et al. Respondent-driven sampling analysis tool (RDSAT) Version 7.1. Ithaca, NY: Cornell University; 2012.

31. Handcock MS, Gile KJ, Fellows IE, et at. Package "RDS." 2015 [cited 2015 Nov 29]; Available from: ftp://204.45.81.82/cran/web/packages/RDS/RDS.pdf.

32. Garten R, Lai S, Zhang J, Liu W, Chen J, Vlahov D, et al. Rapid transmission of hepatitis $C$ virus among young injecting heroin users in Southern China. Int J Epidemiol. 2004:33:182-8.

33. Abdala N, Carney J, Durante A, et al. Estimating the prevalence of syringe-borne and sexually transmitted diseases among injection drug users in St Petersburg, Russia. Int J STD AIDS. 2003;14:697-703.

34. Quaglio G, Lugoboni F, Pajusco B, Sarti M, Talamini G, Mezzelani P, et al. Hepatitis $C$ virus infection prevalence, predictor variables and prevention opportunities among drug users in Italy. J Viral Hepat. 2003:10:394-400.

35. Aceijas C, Rhodes T. Global estimates of prevalence of HCV infection among injecting drug users. Int J Drug Policy. 2007:8:52-358.

36. Nelson P, Mathers BM, Cowie B, Hagan H, Des Jarlais D, Horyniak D, et al. Global epidemiology of hepatitis $B$ and hepatitis $C$ in people who inject drugs: results of systematic reviews. Lancet. 2001;378:571-83.

37. Kapaolia F, Vlahov D, Des Jarlais D, et al. Does bleach disinfection of syringes protect against hepatitis infection among young adult injection drug users? Epidemiology. 2002;13:738-41.

38. Binka N, Paintsill E, Patel A, Lindenbach B, Heimer R. Disinfection of syringes contaminated with hepatitis $C$ virus by rinsing with household products. Open Forum of Infect Dis. 2015:2(1). doi:10.1093/ofid/ofv017.

39. Thorpe $N$, Ouellet $\amalg$, Hershow R, et al. Risk of hepatitis C virus infection among young adult injection drug users who share injection equipment. Am J Epidemiol. 2002;155:645-53.

40. Alter MJ, Kruszon-Moran D, Nainan OV, et al. The prevalence of hepatitis C virus infection in the United States, 1988 through 1994. N Engl J Med. 1999; 341:556-62.

41. Hagan $H$, Thiede $H$, Weiss NS, et al. Sharing drug preparation equipment as a risk factor for hepatitis C. Am J Publ Health. 2001:91(1):42-6.

42. Palmateer $\mathrm{N}$, Hutchinson $\mathrm{S}, \mathrm{McAllister} \mathrm{G}$, et al. Risk of transmission associated with sharing drug injection paraphernalia. J Viral Hepat. 2014;21(1):25-32.

43. Colon HM, Robles RR, Deren S, et al. Between-city variation in frequency of injection among Puerto Rican injection drug users: East Harlem, New York, and Bayamon, Puerto Rico. J Acquir Immune Defic Syndr. 2001;27:405-13.

44. Perez CM, Suarez E, Torres E. Epidemiology of hepatitis $C$ infection and its public health implications in Puerto Rico. PR Health Sci J. 2004:23(2):11-28.

45. Perez C, Marrero E, Melendez M, et al. Seroepidemiology of viral hepatitis, HIV and herpex simplex type 2 in the household population aged 21-64 years in Puerto Rico. BMC Infect Dis. 2010;10:76

46. Strathdee S, Stockman JK. Epidemiology of HIV among injection and noninjection drug users: current trends and implications for interventions. Cur HIV/AIDS Rep. 2010:7:99-106.

47. Grebely J, Mattews GV, Lloyd AR, et al. Elimination of hepatitis C virus infection among people who inject drugs throw treatment as prevention: feasibility and future requirements. Clin Infect Dis. 2013;57(1):1014-20. 
48. Woods E, Kerr T, Motaner J, et al. Rationale for evaluating North America first medically supervised safer-injection facility. The Lancet. 2004;4(5):301-6.

49. Dutta A, Wirtz A, Baral S, et al. Key harm reduction interventions and their impact on the reduction of risk behavior and HIV Incidence among people who inject drugs in low income and middle income countries. Curr Opin HIV AIDS. 2012;7(4):362-8.

50. Page K, Morris MD, Hahn J, et al. Injection drug use and hepatitis C virus infection in young adult injectors: using evidence to inform comprehensive prevention. Clin Infect Dis. 2013;57(2):32-8.

51. Deren S, Gelpí-Acosta C, Albizu-García CE, et al. Addressing the HIV/AIDS epidemic among Puerto Rican people who inject drugs: the need for a multiregion approach. Am J Public Health. 2014;104(11):2030-6.

52. Robertson A, Garfein RS, Wagner KD, et al. Evaluating the impact of Mexico's drug policy reforms on people who inject drugs in Tijuana, B.C., Mexico, and San Diego, CA., United States: a binational mixed methods research agenda. Harm Reduct J. 2014. doi:10.1186/1477-7517-11-4.

Submit your next manuscript to BioMed Central and we will help you at every step:

- We accept pre-submission inquiries

- Our selector tool helps you to find the most relevant journal

- We provide round the clock customer support

- Convenient online submission

- Thorough peer review

- Inclusion in PubMed and all major indexing services

- Maximum visibility for your research

Submit your manuscript at www.biomedcentral.com/submit
Biomed Central 